\title{
EL PROBLEMA DE SELECCIÓN DE LOS MIEMBROS DEL TRIBUNAL CONSTITUCIONAL PERUANO
}

Francisco Tipula Mamani *

\section{INFORMACIÓN DEL ARTÍCULO}

Art. Recibido: $02 / 07 / 2020$

Art. Aceptado: 04/08/2020

Art. Publicado: 10/08/2020 


\section{RESUMEN:}

Mediante el presente artículo se abordara el problema de la selección de los Magistrados del Tribunal Constitucional, previstos en el tercer párrafo del artículo $201^{\circ}$ de la Constitución Política del Perú, para lo cual acudimos a la metodología cualitativo, es decir fue descriptivo y explicativo de teorías e instituciones jurídicas que permitan identificar las características y la interpretación de alcances en la selección adecuada de los magistrados a fin de que pueda garantizar el control constitucional, sin mayor naturaleza política; en tal sentido es necesario establecer los mecanismos constitucionales que permitan la selección democrática de los miembros del Tribunal Constitucional.

Palabras Claves: Jurisdicción constitucional, magistrados, juez constitucional.

\section{THE PROBLEM OF SELECTION OF MEMBERS OF THE PERUVIAN CONSTITUTIONAL COURT}

\section{ABSTRACT:}

This article will address the problem of the selection of judges of the Constitutional Court, provided for in the third paragraph of article 201 of the Political Constitution of Peru, for which we turn to the qualitative methodology, that is to say it was descriptive and explanatory of theories and legal institutions that allow to identify the characteristics and interpretation of scopes in the proper selection of judges so that it can guarantee constitutional control, without further political nature; in this regard, it is necessary to establish constitutional mechanisms that allow the democratic selection of the members of the Constitutional Court.

Keywords: Constitutional jurisdiction, magistrates, constitutional judge. 


\section{INTRODUCCIÓN}

En el Perú contemporáneo, el Tribunal Constitucional, según el artículo $201^{\circ}$ de la Constitución del Estado, es un órgano constitucional autónomo e independiente, es decir no depende de los Poderes del Estado, sino es una instancia creado por el Poder Constituyente, cuya tarea es ejercer una función de hacer respetar las normas constitucionales, es decir, las leyes y actos sean acorde al texto constitucional. Por otro lado, tiene facultad de conocer y resolver en última instancia sobre la protección de los derechos fundamentales de la persona humana, y finalmente dirimir el conflicto de competencias.

En la doctrina, según García Toma (2015, pág. 194), citando a Francisco Morales Saravia, el Tribunal Constitucional es un órgano constitucional, jurisdiccional, colegiado y especializado; por lo tanto para abordar sobre los miembros de este órgano constitucional, es necesario señalar como preámbulo al análisis del tema, sobre la jurisdicción constitucional.

La palabra jurisdicción deriva de la locución latina IURISDICTIO; es decir: IURIS significa ley, derecho; y DICTIO o DICEDERE implica la acción de decir o declarar (Gómez de Silva, 2009), término que se interpreta ampliamente dentro de la teoría del derecho procesal civil, pues la función jurisdiccional, es una de las funciones del Estado, en tal sentido, conforme precisa Carnelutti, citado por Ticona Postigo (1994, pág. 44) la jurisdicción es un poder-deber del Estado, obligado a administrar justicia, componiendo litigios, realizando la interpretación, aplicar la ley a determinado conflicto o incertidumbre jurídica. Por su parte Chanamé Orbe (2010) señala que la jurisdicción constitucional es la potestad para componer los conflictos o controversias del derecho constitucional.

Estando las premisas indicadas, es oportuno remontar históricamente cómo ha evolucionado la jurisdiccional constitucional, al respecto nos remitimos a las sociedades antiguas, como la sociedad romana, donde los mecanismos de control de poder estatal, según Díaz Zegarra (2010) tiene tres etapas: a) En la Monarquía los patricios tenían el control del poder estatal, y es, en esa época surge el asunto de intercessio, por el cual el rey, intercedía ante autoridades inferiores, para restablecer el derecho vulnerado; b) En seguida durante el periodo de la Republica se dio la creación de la institución del Tribuno de la Plebe, instancia que se encargaba de la defensa de los derechos de los plebeyos frente al abuso o exceso de poder estatal; y c) El Imperio, época en la que se instituye el emperador y se aplica la figura jurídica de Interdicto de Homine Libero Exhibendo, consagrado en el Digesto; por el cual protegía el derecho de la libertad personal, dirigido contra las personas particulares que indebida o arbitrariamente retuvieran en su poder a hombres libres.

Llegamos a la edad media, época en la que se produjo la invasión de barbaros, de manera que se practicaba la figura VINDICTA PRIVATA, por el cual cada uno podía hacer justicia por sus propias manos (venganza). Asimismo, se tiene el pensamiento de Santo Tomas de Aquino, quien consideraba que toda clase de ley, era eterna, natural y divina (Mesía Ramírez, 2013). Posteriormente en la época de renacimiento, la costumbre ya no es la única fuente del derecho, y se da realce a la potestad legislativa.

Respecto a la consolidación de la teoría del derecho constitucional, por ende el derecho procesal constitucional, fue en el derecho Británico, en el año de 1215 se firmó la Carta Magna del Rey Juan Sin Tierra, incluso, muchos tratadistas consideran como primera constitución sistematizada, y según la doctrina del Juez Coke se planteaba la teoría de supremacía del Common Law (Fernández Segado). 
Journal homepage: http://revistas.unap.edu.pe/rd/ E-mail: revistaderecho@unap.edu.pe

También en España, durante el reino de Aragón, siglo XII (año 1348) se instituye la JUSTICIA MAYOR, que era un fuero con privilegio general, documento que contenía los mecanismos de: La manifestación de persona, el Juris Firma y la Aprehensión.

En Estados Unidos de Norteamérica, en el año de 1776 se acontece la Declaración de la Independencia y en el año de 1787 se acepta el proyecto de la Constitución.

En Francia, en el año de 1789 se produce la Declaración de los Derechos del Hombre y del Ciudadano, estos y otros aportes que contribuyeron en la consolidación de la teoría del derecho constitucional y del derecho procesal constitucional.

En el caso Peruano, el derecho constitucional fue influenciado por la Constitución de Cádiz de 1812, así como de Estados Unidos; en efecto, el sistema de defensa constitucional, es la teoría desarrollada recientemente.

Dentro de la justicia constitucional encontramos las acciones de garantía constitucional, en defensa de la dignidad de la persona humana, que se expresa en protección de los derechos fundamentales de la persona, y por otro lado las acciones de control constitucional, al cual Kelsen, jurista austriaco denominó como el legislador negativo o poder derogatorio; teoría que desarrolló en dos sistemas de control de la constitucionalidad de las leyes, cuya defensa jurisdiccional de la constitución se dieron en los modelos siguientes:

- Jurisdicción americano, que se caracteriza por ejercer el control difuso o judicial review de la constitucionalidad de la Ley, además es de carácter incidental, eficacia inter partes y es declarativo; es decir el control de supremacía de normas constitucionales está a cargo del propio Poder Judicial y no existe un órgano especializado.

- Mientras que en el modelo europeo denominado también control concentrado o austriaco, se caracteriza la defensa de la constitucionalidad está a cargo de un órgano especializado, que es la Corte o Tribunal Constitucional, cuyo control constitucional se tramita como proceso principal, con eficacia erga omnes y es constitutivo.

Esos son principales modelos de control constitucional, empero a la fecha existe teorías que plantean otros tipos de defensa constitucional, como mixto o paralelo, pero en los países que se tiene instituido la Corte o Tribunal Constitucional, que es un órgano concentrado, esta entidad está conformado por miembros, que en el mundo hay diversas formas de designación o selección, que en algunos incluso ha generado cuestionamientos, cuya teoría se desarrollara en líneas adelante.

\section{MATERIALES Y MÉTODOS}

Revisión documental de textos constitucionales del Perú y derecho constitucional comparado, así como los artículos científicos sobre temas de selección de los magistrados del Tribunal Constitucional. Se realizó la investigación de carácter cualitativo, empleando los métodos de nivel descriptivo y explicativo de principios, normas y teorías de enfoque del derecho constitucional.

\section{RESULTADOS Y DISCUSION}

Realizado el estudio de las Constituciones de Estados, se tiene que hay países que solo ostenta el sistema de control constitucional difuso, es decir cuya función de defensa de normas constitucionales recae solo en los jueces del Poder Judicial, es el modelo instituido por Estados Unidos de Norteamérica.

En Japón, la designación de los jueces de la Corte Suprema se somete a la consideración de los electores en la primera elección general de miembros de la Cámara de Representantes, mientras que los jueces de tribunales inferiores son nombrados por el Gabinete. 
Journal homepage: http://revistas.unap.edu.pe/rd/ E-mail: revistaderecho@unap.edu.pe

Similar contenido se establece en la Constitución de Finlandia de 1999, en su artículo $106^{\circ}$, cuando establece: "Si en un asunto en proceso en un Tribunal la aplicación de una norma con rango de Ley está en evidente contradicción con la Constitución, el Tribunal deberá otorgar jerarquía normativa a la norma constitucional".

Por otro lado, el mecanismo de defensa Constitucional concentrado formulada por Kelsen, sobre la creación de un órgano, denominado el Tribunal Constitucional, el cual por vez primera se incorpora en la Constitución austriaca de 1920 (Pedro de Vega, recopilado por Blancas Bustamante y otros, 1992), instaurándose el modelo europeo; precisamente en el artículo $137^{\circ}$ y siguientes, se crea dicho órgano y compuesto por Presidente, Vicepresidente y seis miembros y tres suplentes nombrado por el Presidente de la Republica y que los restantes designados por el Presidente Federal; se asemeja el sistema de designación de los miembros del Tribunal en Francia, según el artículo $56^{\circ}$ de la Constitución de 1958.

Se ha encontrado también en el régimen de control constitucional de Alemania de 1949, artículo $94^{\circ}$ señala que los miembros del Tribunal Constitucional Federal, en una mitad es designada por la Dieta Federal y la otra mitad elegido por el Consejo Federal.

Mientras que la Constitución de Italia de 1947, establece que los jueces del Tribunal Constitucional, son nombrados por los tres poderes del Estado, son similares: En el artículo $159^{\circ}$ de la Constitución de España de 1978, en el artículo 81 de la Constitución de Chile de 1980 y en la Constitución de 1979 de la República del Perú.

En Cambio, según la Constitución de 1991 de Colombia, los magistrados de la Corte Constitucional son elegidos por el Senado de la Republica; es parecido en la Constitución Peruana de 1993.

Al margen de lo descrito en los puntos anteriores, gran sector de la doctrina considera un modelo mixto o paralelo de control constitucional; al respecto es el caso de Constitución Federal de la Constitución Suiza de 1999, en donde la jurisdicción constitucional, está a cargo del Tribunal Federal que es la autoridad judicial suprema de la Confederación.

También en el caso de la Constitución de la República Federativa de Brasil de 1988, artículo 101 instituye el Supremo Tribunal Federal, compuesto por once Ministros, que es el máximo órgano del Poder Judicial, cuyo modelo de control no es exclusivamente difuso, sino la instancia señalada cumple las funciones de un órgano de control concentrado.

Similar figura se establecía en el artículo 103 de la Constitución de México de 1917, con los Tribunales de la Federación que resuelve en última instancia algunas cuestiones de control constitucional, pero también tiene Tribunales Colegiados de Circuito que asume la jurisdicción constitucional y resuelve en definitiva algunas cuestiones de defensa constitucional.

En el caso de la República del Perú, de las doce constituciones de su época republicana, por primera vez en la Constitución de 1856, en su Título Tercero: Garantías Nacionales, artículo $10^{\circ}$ establece: "Es nula y sin efecto cualquiera ley en cuanto se oponga a la Constitución (...)", es decir, es la norma constitucional que consagra el principio de supremacía constitucional. Analizando la práctica de designaciones de los jueces de la Corte Suprema de Justicia de la República del Perú, encontramos en el artículo $115^{\circ}$ de la Constitución de 1839, precisamente eran nombrados por el Poder Ejecutivo, previa terna propuesta por el Consejo de Estado; pero en la Constitución de 1856, artículo $127^{\circ}$ establecía que los vocales de la Corte Suprema eran nombrados por el Congreso a propuesta del Ejecutivo y demás instancias; continúan similar texto en las Constituciones de 1860,1867 y 1933 , en sus artículos $126^{\circ}, 123^{\circ}$ y $222^{\circ}$, respectivamente. Mientras que en el artículo $148^{\circ}$ de la Constitución de 1920 , los vocales de la Corte Suprema eran 
Journal homepage: http://revistas.unap.edu.pe/rd/ E-mail: revistaderecho@unap.edu.pe

nombrados por el Poder Ejecutivo. En la Constitución de 1979 se crea el Consejo Nacional de la Magistratura, cuyos magistrados eran nombrados por el Presidente de la Republica, conforme se contemplaba en el artículo $245^{\circ}$, organismo que se encargaba de seleccionar a los jueces del Poder Judicial. Por otro lado, también se crea el Tribunal de Garantía Constitucional, que era conformado por nueve miembros, tres designados por el Congreso, tres designados por el Poder Ejecutivo y tres por la Corte Suprema de Justicia, conforme el artículo $296^{\circ}$ de la Constitución precitada. Actualmente, en la Constitución de 1993, los miembros del Tribunal Constitucional, son siete, elegidos solo por el Congreso de la Republica, artículo $201^{\circ}$.

Respecto a la selección de jueces del Poder Judicial, en diciembre de 2018 se consultó vía referéndum sobre la reforma constitucional sobre creación de la Junta Nacional de Justicia, para reemplazar al Consejo Nacional de la Magistratura, el mismo fue aprobado por el pueblo, por lo que mediante la Ley $\mathrm{N}^{\circ} 30904$ se realizó la Reforma Constitucional y se implementó una Comisión Especial para la selección de miembros de la Junta Nacional de Justicia, por concurso de méritos y demás requisitos establecidos en la Ley Orgánica de la Junta Nacional de Justicia, Ley $\mathrm{N}^{\circ} 30916$.

Pero, la elección de los miembros del Tribunal Constitucional, es función del Congreso de la República, precisamente esta figura ha conllevado cuestionamientos no solamente por un sector de la sociedad civil y grupos políticos, sino hubo una advertencia por la Comisión Interamericana de Derechos Humanos, al Congreso para que se garantice la transparencia en la elección de los miembros del Tribunal Constitucional.

Estando a lo precisado, el Presidente de la República con Oficio N ${ }^{\circ}$ 260-2019-PR, de fecha 30 de setiembre de 2019, solicitó vía voto de confianza, la modificación de artículo $8^{\circ}$ de la Ley Orgánica del Tribunal Constitucional - Ley $\mathrm{N}^{\circ} 28301$, previa a la elección de los miembros del Tribunal Constitucional, el mismo no fue tomado en cuenta por el Congreso, lo que ha motivado la disolución del Congreso de la República, cabe resaltar que dicho proyecto de ley entre otros contenía la petición de que el Pleno del Congreso designe una Comisión Especial respetando el principio de pluralidad con un representante por cada grupo parlamentario, además, las sesiones de la Comisión Especial sean públicas y tengan la veeduría de la Defensoría del Pueblo y organismos de la sociedad civil, asimismo luego de etapa de tachas, la Comisión Especial invitará a los candidatos aptos a una audiencia pública, concluida dicha estación se publicará la lista de candidatos aptos para que sean elegidos por el Pleno del Congreso.

\section{Criterios de selección de magistrados del Tribunal Constitucional}

En el caso del modelo norteamericano, según Blancas Bustamante y otros (1995) que cita a Maurice Duverger, en algunos Estados de Estados Unidos se implementó la elección de jueces y como tal, los electores pueden revocar a los jueces mediante la figura de recall y agrega: " $E l$ sistema de los jueces por elección no ha dado buenos resultados", porque:

- No da la garantía necesaria de competencia jurídica

- Y, para las elecciones, los candidatos a las funciones jurisdiccionales ha obligado afiliarse en Partidos Políticos; situación que no aseguraba en nada la garantía de imparcialidad.

Por otro lado, para tener un panorama con garantías de imparcialidad e idoneidad, debemos remitirnos al sustento de perfil de magistrados que señala Gutiérrez Canales, y que son:

1. Trayectoria de vida personal y profesional intachable

2. Compromiso y experiencia en la defensa de los derechos fundamentales, del Estado de Derecho y de la democracia

3. Formación jurídica especializada

4. Independencia e imparcialidad

5. Honestidad e integridad moral

6. Espíritu de servicio 
Journal homepage: http://revistas.unap.edu.pe/rd/ E-mail: revistaderecho@unap.edu.pe

7. Analítico y critico

8. Capacidad lógica jurídica y de argumentación

9. Conocimiento del contexto socioeconómico de la sociedad y capacidad de adaptabilidad al cambio

10. Contar con espíritu creativo.

El perfil señalado es muy importante, porque los magistrados del Tribunal Constitucional no solo deciden sobre la defensa de los derechos fundamentales de la persona humana, sino tiene la tarea compleja de revisar la constitucionalidad de leyes dadas por el Congreso de la Republica, así cono evaluar la garantía del debido proceso, en el actuar jurisdiccional y administrativa; por ello el perfil de dichos magistrados debe ser conocido su honestidad y su formación moral y como precisa Gutiérrez Canales, debe tener "el notable grado de conocimiento del derecho".

En efecto, las designaciones por el Poder Ejecutivo o Poder Legislativo o mixto, consideramos que no es garantía de imparcialidad, por lo que teniendo en cuenta que la Constitución y la Ley Orgánica del Tribunal Constitucional, establecen que para ser miembro del Tribunal Constitucional son los mismos requisitos de los jueces de la Corte Suprema del Poder Judicial, en tal sentido los miembros del Tribunal Constitucional debe ser nombrados (mediante concurso que se practica en Francia, señalado por Blancas Bustamante, citando a Duverger) por la Comisión Especial que selecciona a los miembros de la Junta Nacional de Justicia, mediante concurso de méritos y además tomando en cuenta el perfil señalado en el presente artículo, porque el mecanismo de elección popular tampoco garantizaría la imparcialidad de los miembros del Tribunal Constitucional, porque a la larga puede traer politización partidaria.

\section{CONCLUSIONES}

Habiendo realizado el análisis del derecho constitucional comparado y nacional, así como la doctrina en materia jurídica, la selección y nombramiento de los miembros del Tribunal Constitucional, es diverso, pues por un lado se designa por el Poder Ejecutivo o Poder Legislativo, en algunos es mixto y en otros es realizado por los tres poderes del Estado. Actualmente en la República del Perú, los miembros del Tribunal Constitucional son elegidos por el Congreso de la Republica, figura que ha conllevado cuestionamientos político y jurídico, además no es una garantía como para establecer una seguridad jurídica en el país.

Estando a lo esgrimido, consideramos que la selección y nombramiento de los magistrados del Tribunal Constitucional, debe ser realizado por la Comisión Especial que selecciona a los miembros de la Junta Nacional de Justicia, para lo cual deberá formularse el proyecto de ley de reforma constitucional del artículo 201 de la Constitución Política del Perú de 1993. 
Journal homepage: http://revistas.unap.edu.pe/rd/ E-mail: revistaderecho@unap.edu.pe

\section{REFERENCIA BIBLIOGRÁFICA:}

1. BARKER, Robert S. (2005). La Constitución de los Estados Unidos. APDC - IIDC. Sección Peruana. Lima. 221 pp.

2. BLANCAS BUSTAMANTE, Carlos; LANDA ARROYO, Cesar; y RUBIO CORREA, Marcial (1995). Derecho Constitucional General. Tomo II. Fondo Editorial UPSC. Lima Perú. 597 PP.

3. CHANAME ORBE, Raúl (2010). Diccionario de Derecho Constitucional. Editorial DRUS. Arequipa. 606 pp.

4. DIAZ ZEGARRA, Walter A. (2010). Comentarios al Código Procesal Constitucional. Ediciones Legales. Lima. 878 pp.

5. GARCIA TOMA, Víctor (2015). Constitución, Justicia y Derechos Fundamentales. Grupo Editorial Lex \& Iuris. Lima. 589 pp.

6. GOMEZ DE SILVA, Guido (2009). Diccionario Etimológico de la Lengua Española. Fondo de Cultura Economica. México. 736 pp.

7. MESIA RAMIREZ, Carlos (2013). Exegesis del Código Procesal Constitucional. Tomo I. Gaceta Jurídica. Lima. 846 pp.

8. NUÑEZ RIVERO, Cayetano (2014). La Constitución Española y las fuentes del Derecho Constitucional, Editorial Universitas, S.A. Madrid - España. 385 pp.

9. TICONA POSTIGO, Víctor L. (1994). Código Procesal Civil - Comentarios, materiales de estudio y doctrina. Arequipa. $640 \mathrm{pp}$.

10. Ministerio de Justicia. Colección Constitucional Peruana (2005). Tomos: I, II y III. Primera Edición Oficial - Lima.

11. FERNANDEZ SEGADO, Francisco. Ensayo sobre: Evolución histórica y modelos de control de constitucionalidad.

12. GUTIERREZ CANALES, D. Raúl. Artículo sobre: La elección de miembros del Tribunal Constitucional en el Perú: Una mirada desde el Derecho Europeo y Latinoamericano.

13. Constitución de Austria de 1920 y otros. 